\title{
EL INTERÉS DEL GRUPO DE SOCIEDADES Y LA ACCIÓN RESCISORIA CONCURSAL EN EL DERECHO ESPAÑOL: BREVE REFERENCIA AL DERECHO BRASILEÑO
}

\author{
Lidia Martinez Ruiz e Paulo Roberto Colombo Arnoldi*
}

\begin{abstract}
Sumario: 1. El interés del grupo de sociedades. 1.1 Concepto y legitimación del interés del grupo de sociedades. 1.2. Las instrucciones perjudiciales como medio de alcanzar interés del grupo. 2. La rescisión concursal en el contexto del grupo. 2.1 La irrescindiblidad de los actos ordinarios. 2. 2 La gratuidad de las operaciones del grupo de sociedades. 2.3 La valoración del perjuicio en el grupo de sociedades. 2.3.1 La doctrina de las ventajas compensatorias. 2.3.2 La doctrina de las ventajas compensatorias aplicada a la rescisoria concursal. Conclusión
\end{abstract}

Resumen: El grupo de sociedades en Derecho español constituye una realidad económica no regulada sistemáticamente. En ocasiones, el funcionamiento del grupo requiere una actuación en interés del grupo que puede ser perjudicial para una sociedad miembro. Si esta sociedad es declarada en concurso posteriormente, la administración concursal deberá plantearse la rescisión del aquel acto perjudicial para la sociedad y beneficioso para el grupo. El presente trabajo aborda los problemas que plantea la rescisión concursal de los actos realizados en el contexto del grupo de sociedades, formulando la idea de que la valoración del perjuicio debe hacerse de conformidad con la "doctrina de las ventajas compensatorias".

Palabras clave: Grupo de sociedades. acción rescisoria. interés del grupo. responsabilidad del grupo de sociedades. concurso de acreedores. insolvencia de la filial.

\begin{abstract}
The group of companies under Spanish law is an unregulated economic reality. Sometimes group functioning requires preforming action in the interests of the group that can be detrimental to a singular member. If this company is declared bankrupt, then the administrators should consider reintegration of the act detrimental to the company and beneficial to the group. This paper addresses the problems of bankruptcy reintegration of acts performed in the context of the corporate group, formulating the idea that the injury valuation should be in accordance with the "doctrine of countervailing benefits".

Key words: Group companies. reintegration action. interest group. corporate group liability. Bankruptcy. insolvency of the subsidiary.
\end{abstract}

\section{EL INTERÉS DEL GRUPO DE SOCIEDADES}

\subsection{CONCEPTO Y LEGITIMACIÓN DEL INTERÉS DEL GRUPO DE SOCIEDADES}

Si partimos de que el fenómeno del grupo de sociedades surge cuando varias sociedades se unen y actúan bajo una dirección común, es lógico pensar que dicha dirección debe tener un propósito que no puede ser otro que la consecución de un objetivo económico, con la peculiaridad de que, para la consecución de ese fin, cada una de las sociedades constituye una mera parte del todo; es decir, la empresa pasa de situarse en el plano societario, al plano plurisocietario de manera que la empresa ya no la constituye una sociedad individualmente considerada, sino que la empresa es el grupo $^{1}$. Ese perseguido objetivo económico a cuya consecución la dirección unitaria va a aspirar se denominaría interés del grupo ${ }^{2}$ y se manifiesta en la búsqueda del máximo beneficio conjunto, aunque no necesariamente para todos los miembros.

El propio concepto de grupo de sociedades se encuentra ya recogido en algunas normas sectoriales del ordenamiento español; el legislador no solo no desconoce el fenómeno del grupo, sino que lo reconoce. Y he aquí dónde nos encontramos con la paradoja: de la diversidad de normas que hacen alusión al grupo de sociedades parece desprenderse que el grupo se encuentra, de alguna manera, legitimado; sin embargo, el

\footnotetext{
${ }^{*}$ Lidia Martinez Ruiz é Doctoranda em Derecho Mercantil pela Universidad CEU San Pablo. Paulo Roberto Colombo Arnoldi é Professor Titular do Programa de Pós-graduação em Direito da UNESP.
} 
legislador no le ha otorgado los instrumentos necesarios para su correcto desarrollo.

A diferencia de lo que ocurre en Derecho Español, en Brasil existe una regulación específica sobre los grupos de sociedades de tipo contractual recogida en la Ley 6.404/76 conocida como Ley de Sociedades por Acciones (arts. 265 a 277). Esta regulación obliga a los administradores de las sociedades filiales a observar las instrucciones de los administradores del grupo que no supongan violación de la ley o del contrato de grupo (art 273). Por otro lado, en el ordenamiento brasileño también encontraremos grupos de facto que son aquellos que no se han constituido de conformidad a lo establecido en las normas citadas, por lo que se regularán según lo previsto para las situaciones de control accionarial (arts. 116 a 118) y en las normas del Código Civil (art. 1097 a 1101), específicamente el artículo 1098 que trata las sociedades controladas. La Comisión de Valores Mobiliarios (CVM) considera infracción grave -por disposición del artículo 1 de la instrucción 131 de 17.8.1990 y sancionada con las penas previstas en los incisos $3^{\circ}$ y $6^{\circ}$ de la Ley 6385/76- el incumplimiento de los preceptos relacionados con la regulación del grupo de sociedades y las relaciones de control societario ( arts. $117,153,1541^{\circ}$ y $2^{\circ}, 1551^{\circ}$ y $2^{\circ}, 156.1^{\circ}$, $165,201,202.5^{\circ}, 245,254.1^{\circ}$ y $2^{\circ} 255.1^{\circ}$ y $2^{\circ}, 266$ y 273 de la Ley $\left.6.404 / 76\right)$.

El problema del grupo en Derecho español se concreta en la dificultad de poder legitimar la actuación del conjunto de las sociedades que lo forman en orden a la consecución del interés común o interés del grupo, máxime cuando alguna de estas pudiera resultar perjudicada a consecuencia de una instrucción perjudicial, produciéndose conflicto de intereses en su seno: el del grupo de sociedades como empresa plurisocietaria y el de la sociedad individual. Es por ello que la verdadera problemática del fenómeno no subyace tanto en declarar legítimo, o no, el ejercicio de ese poder de dirección externo a la sociedad, como en admitir que tal poder se dirija a la consecución de un interés distinto -el interés del grupo- que en algunas ocasiones será contrario al interés individual de las sociedades agrupadas ${ }^{3}$.

\subsection{LAS INSTRUCCIONES PERJUDICIALES COMO MEDIO DE ALCANZAR INTERÉS DEL GRUPO}

Será perjudicial aquella instrucción que impartida por la matriz provoque una disminución efectiva o un peligro real para el patrimonio de la sociedad filial afectada, siempre y cuando se emita en interés del grupo. En sentido amplio, ha de entenderse por instrucción cualquier medida adoptada por la sociedad matriz mediante la cual quiere influir e influye en la gestión de la sociedad filial, incluyendo no solo las instrucciones en sentido estricto (órdenes), sino también cualquier otro tipo de declaración de voluntad de la matriz (consejos, directivas, recomendaciones, etc.) en virtud de las cuales la sociedad filial se vea obligada a modificar su comportamiento adecuándolo a las directrices de la matriz ${ }^{4}$. Una instrucción perjudicial es aquella que obliga a tomar una serie de medidas que un administrador de una sociedad independiente que actuara diligentemente en interés de su sociedad no adoptaría. Estas instrucciones se materializarán habitualmente en la celebración de negocios jurídicos o en la adopción de determinadas medidas o actos por la sociedad filial, -ya se trate de un comportamiento activo o pasivo- ${ }^{5}$.

En determinadas ocasiones, la realidad del tráfico impone que sea necesario llevar a cabo un acto perjudicial para una de las sociedades del grupo si este acto trae como resultado un beneficio mayor para el conjunto de la empresa plurisocietaria. Se 
plantea entonces la cuestión de si al amparo del interés del grupo -tácitamente reconocido en nuestro ordenamiento- es legítimo que la dirección unitaria del grupo imparta instrucciones que se traduzcan en actos perjudiciales para alguna de las sociedades integrantes. La cuestión no es sencilla si se tiene en cuenta que las instrucciones perjudiciales plantean un problema de conflicto de intereses al colisionar con el deber de fidelidad de los administradores de la sociedad que las reciben.

Ante la problemática del conflicto de intereses, y a falta de un régimen jurídico ad hoc que lo resuelva, la mayoría de la doctrina ha concluido que la legitimidad del grupo de sociedades se dará en tanto no vulnere el ordenamiento societario vigente ${ }^{6}$. La consecución del interés del grupo no puede perjudicar el interés particular de ninguno de sus miembros, por lo que sus efectos deberán ser positivos o, cuando menos, neutros para el interés particular de cada una de las sociedades integradas en él. Por más que se apele al interés del grupo, no resulta justificado que en el derecho español se pueda perjudicar a una sociedad sin una efectiva compensación.

\section{LA RESCISIÓN CONCURSAL EN EL CONTEXTO DEL GRUPO}

Además de los conocidos desajustes organizativos y de transferencia de poderes patológicos en el grupo, la sociedad de grupo también puede sufrir anomalías en el plano patrimonial; la autonomía de cada sociedad queda expuesta al riesgo permanente de resultar desbaratada por las políticas de transferencias que tienen lugar dentro del grupo ejercidas por la dirección unitaria: transferencia de activos de una sociedad a otra, transferencias de capitales, transferencia de personal o transferencia de pérdidas o ganancias para hacer aflorar los beneficios allí donde resulte más conveniente ${ }^{7}$. En este contexto, el problema del conflicto de intereses en el seno de grupo de sociedades se agrava si se entra a considerar los intereses de terceros que, como resultado de esa política de grupo, pueden verse perjudicados, especialmente en situaciones en las que la sociedad de grupo -que ha quedado afectada en el plano patrimonial- deviene insolvente.

La acción rescisoria concursal es una institución fundamental en el procedimiento concursal español, pues permite traer a la masa aquellos activos que injustificadamente salieron de ella en un periodo de dos años anterior a la declaración del concurso como consecuencia de actos de la concursada perjudiciales para la masa (art. 71 LC). Así las cosas, la rescisoria concursal se configura como una herramienta útil para "deshacer", en beneficio de los acreedores, aquellos actos perjudiciales para sí que la concursada realizó en el contexto de la política de grupo -que no podemos sino pensar que fueron instruidos por la dirección unitaria-. Sin embargo, aquellos actos pudieron ser económicamente razonables para la empresa plurisocietaria y beneficiosos para el interés del grupo; de ahí que, en ocasiones -y de manera supreflua- se trate de apelar a este interés del grupo para justificar la irrescindibildad de aquellos.

En Derecho brasileño, la acción rescisoria es tratada como acción revocatoria regulada en la legislación concursal (Ley de falencias y recuperación judicial y extrajudicial, lei 11101/2005, sección IX, arts. 129 a 138). Esta regulación, por un lado, señala una serie de supuestos en los que, probada la realización de un acto dentro de un término, aquel será declarado ineficaz de oficio (constitución de garantía por deuda preexistente, o actos a título gratuito, etc. -art.129-); y, por otro lado, establece una norma para la rescisión de actos realizados con la intención de perjudicar a los acreedores, respecto a los cuales habrá que probar tanto el consilium fraudis entre las 
partes como el efectivo perjuicio sufrido por la masa (art.130).

\subsection{LA IRRESCINDIBLIDAD DE LOS ACTOS ORDINARIOS}

La Ley Concursal español limita el ámbito de la acción rescisoria estableciendo la irrescindibilidad de los actos ordinarios de la actividad empresarial realizados en condiciones normales (art. 71.5-1 ${ }^{\circ}$ LC). Dos son los requisitos que debe reunir el acto para ser subsumido en este supuesto: (i) no puede consistir en un acto de gestión extraordinaria, ni estar fuera de las operaciones habituales de la empresa, y (ii) debe de haberse celebrado de la manera habitual de llevar a cabo ese tipo de operaciones. Se ha asimilado la noción de operaciones ordinarias de una empresa a aquellas propias o contenidas en el objeto social de la sociedad, es decir, a aquellos actos propios del giro o trafico ordinario del deudor. Se trata de un límite a la acción rescisoria concursal en pos de la seguridad jurídica, por lo que, aun cuando estos actos se hayan realizado entre sociedades del grupo no van a quedar afectados por la acción de reintegración.

Ahora bien, habida cuenta de que el grupo de sociedades no es sino una empresa plurisocietaria, cabe preguntarse si, en el contexto del grupo, se debe reinterpretar el concepto de operaciones ordinarias en condiciones normales, y adaptarlo a la praxis y necesidades del grupo, es decir, considerar no rescindibles determinados actos ordinarios o comunes en el funcionamiento de este ente ${ }^{8}$. Como ejemplo de acto $<<$ ordinario〉> en el contexto del grupo se encuentra la -frecuente- fijación de precios en condiciones inferiores a las de mercado entre las sociedades miembro.

Sin embargo, no se ha de olvidar que, aun actuando el grupo como una única entidad económica, cada una de las sociedades conserva su independencia jurídica y patrimonial. El sujeto del concurso es la sociedad individual y, por ello, solo puede entenderse que $<<\operatorname{los}$ actos ordinarios de la actividad empresarial del deudor $>>$ constituyen actos en desarrollo del propio objeto social de la sociedad concursada, que es el único deudor. Por otro lado, como ha entendido algún autor ${ }^{9}$, un acto ordinario de la actividad de la empresa realizado en condiciones normales nunca puede ser perjudicial.

\subsection{LA GRATUIDAD DE LAS OPERACIONES DEL GRUPO DE SOCIEDADES}

Por otro lado, la Ley Concursal establece la presunción iuris et de iure de perjuicio para los actos dispositivos a título gratuito (art. 71.2 LC). El fundamento se encuentra en el carácter manifiestamente perjudicial para la masa activa que resulta de las disposiciones de este tipo, amparada en el principio básico que dogmatiza la menor tutela que merecen las adquisiciones a título gratuito ${ }^{10}$.

Una de las operaciones entre sociedades del grupo que más frecuentemente es examinada bajo los presupuestos de la rescisión es la constitución de garantías por una sociedad del grupo a favor de un tercero con el fin de asegurar obligaciones de otra sociedad del grupo. Cuando la primera de estas es declarada en concurso, no es extraño plantearse la rescisión de la garantía al amparo de la presunción irrefutable de perjuicio con base en una interpretable gratuidad del acto (art. 71.2 LC).

No parece adecuado calificar como gratuito todo acto por el que se otorguen garantías de deuda ajena en el contexto del grupo, pues no lo será la constitución de una garantía por una matriz en apoyo a una de sus filiales. Esta afirmación es aún más evidente en casos de grupos de sociedades jerárquicos en los que la matriz es titular de participaciones de la filial. Los beneficios de la filial -que presumiblemente se quieren 
maximizar- redundarán en provecho de la matriz.

Más dudoso es el caso contrario, en el que la filial otorga la garantía sin contraprestación a favor de otra sociedad del grupo. Los tribunales suelen considerarlo un acto gratuito y son reticentes a aceptar que las ventajas derivadas de la pertenencia al mismo neutralicen la gratuidad. Sin embargo, no parece descabellado plantearse que dichas ventajas -máxime si, por ejemplo, ha permitido a la sociedad concursada dotarse de recursos financieros o acceder a determinados contratos- puedan efectivamente desvirtuar la gratuidad del acto; o que, incluso, al constituir el grupo de sociedades una única empresa plurisocietaria que tiene un interés propio, resulte contradictorio considerar gratuita una operación realizada en interés de grupo.

No obstante, aun pudiendo cuestionar la gratuidad de un determinado acto entre -o a favor- de sociedades del grupo, será determinante si, -aun oneroso- el acto resulta perjudicial para la masa ${ }^{11}$. Por otro lado, no se ha de olvidar que en caso de que el acto se haya realizado entre las sociedades del grupo, la parte actora sigue contando con la presunción iuris tamtum de perjuicio que se establece con motivo de la especial relación de las partes $\left(71.3-1^{\circ} \mathrm{LC}\right)$.

En la regulación brasileña también se contempla la rescisión de los actos realizados a título gratuito dentro de los dos años anteriores a la declaración del concurso que sean de un valor determinante para los intereses de los acreedores (art. 129.IV lei 11101/05).

\subsection{LA VALORACIÓN DEL PERJUICIO EN EL GRUPO DE SOCIEDADES}

Cabe plantearse si de la propia existencia del grupo y la complejidad de las relaciones que se establecen de manera habitual entre sus miembros como resultado de la dirección unitaria en interés del grupo, debe resultar en un examen del concepto del perjuicio de los actos intragrupo bajo unos parámetros idénticos que si de una "sociedad isla" se tratase, o si por el contrario se debe examinar la operación desde una perspectiva diferente.

\section{3.1 La doctrina de las ventajas compensatorias}

Los ordenamientos que se han ocupado de regular el fenómeno de los grupos de sociedades han reconocido la existencia de un interés de grupo y han tratado salvaguardarlo articulando mecanismos que permitan su consecución a la vez que se protegen intereses de terceros ${ }^{12}$. Para ello se ha recurrido a la llamada doctrina de las ventajas compensatorias que legitima la injerencia de un perjuicio a una sociedad integrada en un grupo siempre que de la operación se derive un beneficio para el conjunto y la sociedad perjudicada sea efectivamente compensada por la desventaja sufrida; para ello se debe hacer un balance entre los sacrificios y ventajas que la pertenencia al grupo supone para esa sociedad. Aunque en aplicación de la doctrina de las ventajas compensatorias el juicio sobre la legitimidad de la dirección unitaria sigue dependiendo de que el interés de la sociedad filial no se vea perjudicado, lo determinante es la incorporación de una valoración distinta sobre el respeto a tal interés, teniendo en cuenta no a la sociedad del grupo aisladamente, sino, al conjunto de relaciones en que se halla involucrada.

Para que la doctrina resulte aplicable habrían de cumplirse determinados requisitos: (i) ha de tratarse de una operación resultado de una política de grupo y realizada en interés del grupo, (ii) debe de preverse una compensación adecuada, y (iii) 
el acto perjudicial debe respetar la supervivencia de la sociedad, es decir, esa instrucción o acto no podrá ser determinante de que la sociedad quede en estado de insolvencia ${ }^{13}$.

Aunque la doctrina de las ventajas compensatorias no es desconocida en nuestro derecho proyectado, pues su aplicación ya fue planteada e incluida en el borrador del proyecto del Código de Sociedades Mercantiles, se plantea si esta teoría es aplicable en nuestro ordenamiento sin necesidad de una reforma legislativa. La aplicabilidad de esta teoría en nuestro Derecho de sociedades podría contar principalmente con dos obstáculos; (i)La prohibición de la compensatio lucri cum damno ex artículo 1686 del Código Civil y (ii) El deber de fidelidad del administrador; sin embargo, quien se ha ocupado de estudiar la cuestión no ha encontrado óbice a que ésta se aplique lege lata en nuestro ordenamiento. Por lo que respecta a la primera cuestión, ha de entenderse que la desventaja no es un daño o un perjuicio, si no un valor de contraprestación. De este modo, sólo cuando la desventaja no se compensada en tiempo y forma oportuna, se considerará que se ha ocasionado un daño, y, el deber jurídico de compensación se transformará en una obligación de indemnizar por los perjuicios causados. El otro gran obstáculo, el deber fidelidad que recae sobre el administrador de la sociedad filial que ha de acatar la instrucción perjudicial quedaría salvado al reinterpretar el principio de interés social de un modo más amplio, considerando que tal interés debe de ser concebido como un interés consciente de su necesaria coordinación con un interés global de la empresa que constituye el grupo. Así, la contradicción que supone el enfrentamiento del interés social que cada sociedad del grupo persigue y los sacrificios que le son exigidos en nombre del interés común, es superada a través de la disociación temporal de la noción de interés social, puesto que si la sociedad comente un acto contrario a su interés social inmediato a favor de interés del grupo está, en realidad, persiguiendo su interés social propio en la medida en que puede razonablemente atender una contrapartida futura por este sacrificio ${ }^{14}$.

Aun habiendo sido identificada la teoría de las ventajas compensatorias como la solución idónea al conflicto de intereses intragrupo, no existe en la doctrina, jurisprudencia y legislación comparada consenso en torno a lo que se debe considerar una adecuada compensación. En términos generales, distinguimos dos corrientes: (i) la teoría cuantitativa, y (ii) la teoría cualitativa, caracterizada por una mayor flexibilidad ${ }^{15}$.

La posición cuantitativa, paradigmática del ordenamiento alemán, requiere que el otorgamiento de la ventaja deje a la sociedad como si nunca la hubiesen sufrido desventaja alguna, lo que exige que el perjuicio se compense por completo y, si no de forma simultánea, sí muy cercana en el tiempo. Esta posición ha sido objeto de críticas al entenderse que exigir un rígida identificación cuantitativa entre ventaja y desventaja significa desconocer la realidad del grupo, pues, subordinar la legitimidad de la consecución del interés del grupo a la obtención de un resultado económico equivalente al que se habría obtenido de haber sido la sociedad independiente refleja la idea tradicional de que el interés del grupo se justifica en tanto haya una ausencia de perjuicio para la filial.

La postura que defiende una compensación cualitativa parte de una concepción en la que prima el funcionamiento del grupo como empresa en la que cada sociedad en él integrada no es sin una pieza más destinada a favorecer la riqueza del conjunto, propugnándose una teoría de la compensación que se basa en un procedimiento valorativo asentado en la racionalidad, coherencia y eficiencia del acto -aun cuando sea perjudicial para la sociedad- respecto de una mejoría económica general de grupo a 
medio y largo plazo, de la cual razonablemente, puede derivar una ventaja para la sociedad en cuestión, aun cuando sea sobre planos económicos o momentos distintos respecto de aquel en que tuvo lugar la operación, y también, según un parámetro no rígidamente proporcional ni necesariamente cuantitativo ${ }^{16}$. El referente legislativo de esta posición es el ordenamiento italiano, si bien con mayor claridad en el ámbito penal que en el civil.

Ahora bien, quien defiende la aplicabilidad de la doctrina de la ventajas compensatoria basada en una valoración cualitativa del la compensación no por ello deja de considerar que aquella compensación, aunque no sea cuantitativa, sí debe ser proporcional, ya que únicamente la relación proporcional entre ventajas y desventajas convertirá la compensación en adecuada y justificará la adopción por parte de la sociedad de grupo de medidas desventajosas para su propio interés. La compensación también debe ser cierta, es decir, que no sea hipotética o virtual ${ }^{17}$.

\subsubsection{La doctrina de las ventajas compensatorias aplicada a la rescisoria concursal}

La aplicación de la doctrina de las ventajas compensatorias en sede de rescisoria concursal supondría realizar una interpretación de la noción de perjuicio utilizando el mismo principio empleado para valorar el respeto a la noción de interés social: la disociación temporal del concepto de perjuicio.

No se habría de considerar que un acto concreto ha producido un perjuicio o un daño para la masa del concurso si, con posterioridad, ha sido compensado. Así las cosas, no solo debemos limitarnos a examinar el acto concreto, sino que deberá ponerse en relación con las ventajas que se encuentren vinculadas a él, es decir, deberá tenerse en cuenta el resultado global de la operación política de grupo. Este acto en concreto ha podido suponer una desventaja que posteriormente se ha compensado con una ventaja. De esta manera, y a favor de la postura que aboga por una teoría de la compensación cualitativa pero proporcional y cierta, sólo existirá un perjuicio cuando, habiendo transcurrido el tiempo en el que la desventaja hubo de ser compensada, no lo ha sido, o bien lo ha sido de forma no proporcional.

Algunos autores españoles ya se han mostrado favorables a que, en el ámbito del grupo se valore -lege ferenda- la razonabilidad de la operación en términos económicos empresariales teniendo en cuenta lo que significa el funcionamiento del grupo $^{18}$. Sin embargo, la aplicación de la teoría expuesta al ámbito de la rescisoria sobre la base de la disociación temporal del perjuicio no requiere modificación legislativa alguna $^{19}$; se requiere una noción de compensación basada en la teoría cualitativa -que no cuantitativa-, que se basa en un procedimiento valorativo técnico de carácter económico-funcional, teniendo en cuenta las circunstancias que existían en el momento en que la operación se realizó, atendiendo a la racionalidad y coherencia del acto respecto de una política económica general del grupo a medio y largo plazo, de la cual ha resultado una ventaja para la sociedad en cuestión $^{20}$, siempre que esa ventaja sea proporcional y se llegue a producir y siempre que el acto en cuestión no haya sido determinante de la situación de insolvencia.

La aplicación de la teoría de las ventajas compensatorias a los efectos de examinar los presupuestos para el ejercicio de la acción rescisoria concursal permitiría amparar tanto el interés del concurso (la satisfacción de acreedores) que, no puede -ni debe- verse alterado por la existencia de una relación de grupo, como el propio interés del grupo de sociedades, al que se le concedería un margen razonable de actuación para 
la consecución de sus fines empresariales.

En el caso en el que se estime la procedencia de la rescisión de un acto $-\mathrm{u}$ omisión- considerado perjudicial para la masa del concurso (pues no ha sido debidamente compensado), el acto atacado devendría ineficaz. Sin embargo, teniendo en cuenta la complejidad de las relaciones y operaciones intragrupo, parece razonable plantearse que la parte legitimada pueda llegar a un acuerdo (transacción) con la contraparte o, incluso, un tercero -la matriz del grupo- para <<neutralizar >> dicho perjuicio mediante una compensación adecuada sin necesidad de impugnar el acto. Este tercero podría encontrar la motivación en la necesidad de amparar el interés del grupo si la rescisión pudiera repercutir de forma negativa en otra operación más compleja articulada por la dirección unitaria fruto de una política de grupo.

\section{CONCLUSIÓN}

La apelación al interés del grupo o la mención de la ventaja indeterminada que ha podido obtener la sociedad concursada por la mera pertenencia a éste no permite justificar el perjuicio que a la masa del concurso ha podido ocasionar un acto; por el contrario, se habría de realizar una correcta valoración de la operación en su conjunto, analizando si dicho perjuicio ha sido compensado cualitativamente con una ventaja cierta y proporcional bajo los parámetros de la doctrina de las ventajas compensatorias. No obstante, parece necesario articular de una vez por todas un régimen de grupo en el Derecho de sociedades español; solo así, desde una regulación societaria que legitime el interés del grupo y que prevea, a la vez, mecanismos tuitivos de los intereses de terceros, se podrá lograr una solución satisfactoria para los problemas que el grupo de sociedades plantea en sede concursal. 


\section{BIBLIOGRAFÍA}

BELTRÁN SÁNCHEZ. “Algunas consideraciones sobre la composición del patrimonio concursal" en Estudios sobre el anteproyecto de Ley Concursal de 2001, VV. AA, Madrid, 2004.

DE ARRIBA FERNÁNDEZ. Derecho de grupos de sociedades. Madrid, (Civitas) 2004.

EMBID IRUJO. Introducción al derecho de los grupos de sociedades. Granada, (Comares), 2003.

FUENTES NAHARRO. Grupo de sociedades y protección de acreedores. Una perspectiva societaria. Cizur Menor, (Civitas), 2007

GARCÍA-CRUCES. La reintegración de la masa activa en la Ley Concursal” en Las claves de la Ley Concursal, en Quintana Carlo, Bonet Navarro, García-Cruces (Dirs.), Pamplona, Aranzadi, 2005

GIRGADO PERANDONES. La empresa del grupo y el derecho de sociedades. Granada, (Comares), 2001, pág. 277

GIRÓN TENA en Tendencias actuales y reforma del derecho mercantil (Estudios), Cívitas, 1986

MONTANELI "Conflitto di interesse nei gruppi di società e teoría dei vantaggi compensativi" en VV.AA I gruppi di società (Atti del convengo internazionale di studi), Venezia, 16-17-18 novembre 1995, II, Giuffrè, Milano.

PAZ-AREZ en Uría/Menéndez (dirs.) Curso de Derecho Mercantil 2a ed., Madrid, (Civitas), 2006, Tomo I, págs.1470-1491

SÁNCHEZ-CALERO GUILARTE en. "Algunas cuestiones concursales relativas a los grupos de sociedades" en Anuario de Derecho Concursal, $\mathrm{n}^{\circ} 5$ (2005)

SARAZÁ GIMENA, "Responsabilidad concursal y grupos de sociedades", Anuario de Derecho Concursal, núm. 10, 2007

\footnotetext{
${ }^{1}$ Ya el profesor GIRÓN TENA en Tendencias actuales y reforma del derecho mercantil (Estudios), Cívitas, 1986, pág. 202 se refirió al grupo con el término "superempresa".

${ }^{2} \mathrm{El}$ concepto de interés de grupo no resulta extraño en la literatura jurídica española, muchos son los autores que se han preocupado por estudiar el alcance, significado y legitimidad del mismo, y es que, en efecto, el problema nace de la circunstancia de que nuestro derecho de sociedades está configurado para que sea una sola persona jurídica la que desarrolle una actividad económica y, por lo tanto, todo el régimen jurídico para su funcionamiento queda articulado torno a esta previsión. Es precisamente aquí donde el derecho colisiona con la realidad.

${ }^{3}$ FUENTES NAHARRO, Grupo de sociedades y protección de acreedores. Una perspectiva societaria, Cizur Menor, (Civitas), 2007, pág.134. La autora sitúa en este ámbito (la actuación en interés distinto) el problema del grupo de sociedades, pues considera que la existencia de un poder de dirección externo no es obstáculo en el ordenamiento español, en el que se reconoce la posibilidad de llevar a cabo un poder de
} 
dirección proveniente de instancias diferentes al órgano de administración de la sociedad, por ejemplo: la posibilidad de que la Junta pueda impartir instrucciones vinculantes o el reconocimiento que el legislador hace en el artículo 78 de la Ley de cooperativas de que existen sociedades dominantes que pueden ejercer su influencia sobre otras.

${ }^{4}$ DE ARRIBA FERNÁNDEZ, Derecho de grupos de sociedades, Madrid, (Civitas) 2004, pág., 247, y doctrina citada por la autora.

${ }^{5}$ DE ARRIBA FERNÁNDEZ. Derecho de grupos ... cit. Págs., 403-404.

${ }^{6}$ En este sentido EMBID IRUJO, Introducción al derecho de los grupos de sociedades, Granada, (Comares), 2003, pág. 32; GIRGADO PERANDONES, La empresa del grupo y el derecho de sociedades, Granada, (Comares), 2001, pág. 277; SÁNCHEZ-CALERO GUILARTE en. "Algunas cuestiones concursales relativas a los grupos de sociedades" en Anuario de Derecho Concursal, ${ }^{\circ} 5$ (2005) págs. 7 a 70; FUENTES NAHARRO, Grupos de sociedades y... cit. págs. 146 a 151.

${ }^{7}$ Vid. PAZ-AREZ en Uría/Menéndez (dirs.) Curso de Derecho Mercantil $2^{\mathrm{a}}$ ed., Madrid, (Civitas), 2006, Tomo I, págs.1470-1491.

${ }^{8}$ Vid. SÁNCHEZ-CALERO GUILARTE, "Algunas cuestiones concursales relativas a los grupos de sociedades", Anuario de Derecho Concursal, núm., 5 (2005) págs. 7 a 60 . El autor parece posicionarse a favor de la irrescindibilidad de las operaciones intragrupo en condiciones normales: "Estas acciones no deberán ejercitarse frente a aquellas operaciones justificables por el interés de grupo como actos ordinarios de la actividad empresarial". La tercera parte de la Guía Legislativa sobre Insolvencia de la CNUDMI también se hace eco de este problema señalando que: "algunas operaciones tenidas por legítimas en el seno del grupo de empresas pudieran no estar comercialmente justificadas fuera de este contexto, si se analizan a la luz de las condiciones comerciales normales" (nota de la secretaría, apartados 75 a 82, con referencia a las recomendaciones 87 a 99 págs. 43-46, y recomendaciones 217 y 218). En contra, SARAZÁ GIMENA, "Responsabilidad concursal y grupos de sociedades", Anuario de Derecho Concursal, núm. 10, 2007, quien se opone a la posición del profesor SÁNCHEZ CALERO argumentando que "el simple acto de que se trata de una operación intersocietaria realizada en interés del grupo no transmuta su naturaleza de acto no ordinario o realizado de modo no perjudicial para los acreedores [...] el interés de los acreedores, que es el que primordialmente debe defender los administradores concursales, primeros legitimados para ejercitar estas acciones, no puede verse desplazado en este extremo por el interés del grupo".

${ }^{9}$ Vid. BELTRÁN SÁNCHEZ, "Algunas consideraciones sobre la composición del patrimonio concursal" en Estudios sobre el anteproyecto de Ley Concursal de 2001, VV. AA, Madrid, 2004, pág. 4391.

${ }^{10}$ Vid. GARCÍA-CRUCES, "La reintegración de la masa activa en la Ley Concursal" en Las claves de la Ley Concursal, en Quintana Carlo, Bonet Navarro, García-Cruces (Dirs.), Pamplona, Aranzadi, 2005 , pág. 359.

${ }^{11}$ Queda a salvo lo dispuesto por el artículo 10 de la Ley 2/1981 de Regulación del Mercado Hipotecario.

${ }^{12}$ En el derecho comparado, la doctrina de las ventajas compensatorias tuvo su origen y posterior desarrollo en la labor de la jurisprudencia. En el caso de Italia, esa doctrina fue llevada a los textos legales en el 2003. También se encuentra presente en el ordenamiento alemán, aunque el principio se materializa de forma diferente en función del tipo de grupo que se trate (contractual, fáctico o por incorporación).

${ }^{13}$ FUENTES NAHARRO, Grupos de sociedades y..., cit., pág. 152 y doctrina extranjera citada por ella.

${ }^{14}$ De esta problemática se ha ocupado en profundidad FUENTES NAHARRO en Grupo de sociedades... y doctrina extranjera por ella citada.

${ }^{15}$ Sobre la cuestión, en profundidad, FUENTES NAHARRO, Grupos de sociedades y... págs.155 a 194.

${ }^{16}$ MONTANELI, "Conflitto de interesse nei gruppi di societá e teoria dei vantaggi compensativi $>$ en VV.AA. I gruppi di societá (Atti del convengo internazionali di studi), Venecia, 16-17-18 novembre 1995, II, (Giuffrè), Milano, 1996, págs. 1627 y ss, pág. 1643 citado por FUENTES NAHARRO, Grupos de sociedades $y$.. cit.

${ }^{17}$ FUENTES NAHARRO, Grupos de sociedades y... págs. 173-174 defiende la aplicabilidad en nuestro ordenamiento de una postura en la que la compensación sea cualitativa, proporcional y cierta.

${ }^{18}$ SÁNCHEZ CALERO, "La insolvencia de los grupos en los trabajos de la CNUDMI y el derecho concursal español” en Anuario de Derecho Concursal, núm. 22, 2001, págs. 9-46, se pronuncia así: “Una vez más, la necesidad de de una adecuada interpretación de lo que significa el funcionamiento del grupo en sus aspectos comercial, financiero o patrimonial es un presupuesto necesario para no aplicar, sin más, la posibilidad de impugnación de operaciones por el mero hecho de haberse concretado en el seno del grupo, como indica la recomendación 217 [de la guía legislativa de la CNUDMI] debería existir una previsión legislativa que autorice al Tribunal competente para resolver cualquier acción de 
impugnación, analizar diversas circunstancias que permitan determinar si se está ante una operación razonable en términos económicos empresariales y que, por tanto, su validez y eficacia no deben ser cuestionadas o si, por esas mismas circunstancias, las rescisión está fundamentada".

${ }^{19}$ Aunque habría de realizarse una interpretación extensiva de lo que por "acto del concursado" (art. 71 LC) debe entenderse.

${ }^{20}$ Vid. MONTANELI "Conflitto di interesse nei gruppi di società e teoría dei vantaggi compensativi” en VV.AA I gruppi di società (Atti del convengo internazionale di studi), Venezia, 16-17-18 novembre 1995 , II, Giuffrè, Milano, 1996, págs 1642, citado por FUENTES NAHARRO, Grupos de sociedades y..., cit., pág. 165 , nota 287. 